\title{
eLyra
}

\section{A natureza variável das palavras: \\ A colagem poética na poesia de Carlos de Oliveira}

\author{
Patrícia Resende Pereira \\ Universidade Federal de Minas Gerais
}

Resumo: O propósito do estudo é discutir a maneira com a qual Carlos de Oliveira emprega o recurso da colagem poética em dois textos: "Retrato do autor por Camilo Pessanha (colagem)", publicado em Terra de Harmonia (1950), e "Colagem com versos de Desnos, Maiakovski e Rilke", de Sobre o Lado Esquerdo (1968). A escolha se deve ao fato de que ambos são declaradamente colagens, como informa o título de cada um deles. $\mathrm{Na}$ investigação, intenciona-se perceber como o poeta da Gândara tem condições de dialogar com a obra de outros autores, de modo a criar um texto seu. Assim sendo, percebe-se, para mencionar os dizeres do poema “Lavoisier", também publicado em Sobre o Lado Esquerdo, que cada poema pode, enfim, sonhar outra forma, o que revela um aspecto intertextual da poesia de Carlos de Oliveira.

Palavras-chave: Carlos de Oliveira; colagem poética; intertextualidade

Abstract: This researh studies how Carlos de Oliveira uses the poetic collage in the proccess of writting of two poems: "Retrato do autor por Camilo Pessanha (colagem)", published in Terra de Harmonia (1950), and “Colagem com versos de Desnos, Maiakovski e Rilke", published in Sobre o Lado Esquerdo (1968). We decided to chose those poems because both of them are collages, as we can know only by the title. In this study, the purpose is to find out how Carlos de Oliveira's work dialogues with other author's books, in order to create another text. Thus, we can see, as we are informed by the poem "Lavoisier", also published in Sobre o Lado 
Esquerdo, that each poem can, finally, dream another form, which reveals an intertextual aspect of Carlos de Oliveira's poetry.

Keywords: Carlos de Oliveira; poetic collage; intertextuality

\section{Introdução}

Dito de outro lado, a literatura faz-se com "as palavras dos outros»

(Manuel Gusmão)

Lembra o crítico e poeta Manuel Gusmão (2011), ao citar os versos de Friedrich Hölderlin, em "Da resistência à literatura": "«desde que somos um diálogo» e uma vez que «rico em méritos, é no entanto poeticamente que o homem habita nesta terra»" (Hölderlin apud Gusmão 2011: 36). É em razão de sermos um diálogo que há a possibilidade de existir poesia, pois é ela um "produto directo, dilecto, da consciência humana" (Oliveira 1995: 201), para aproveitar o que diz Carlos de Oliveira no texto "Coisas desencadeadas", de O Aprendiz de Feiticeiro. Como fruto da consciência humana, "a poesia evolui, experimenta, liberta-se" (Oliveira 1995: 201), como dá a ver o poeta em "Lavoisier", poema cujo título, ao evocar o nome do químico francês Antoine Laurent de Lavoisier, incita a pensar o processo de transformação constante do fazer poético:

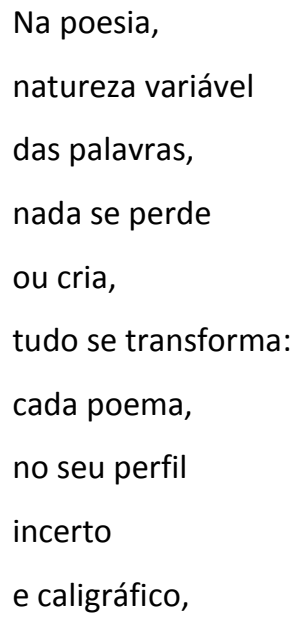


já sonha

outra forma. (Oliveira 2003: 201)

Chama a atenção, em um primeiro momento, o fato de que o poema, por encenar um processo de transformação, é também ele o resultado de uma. Isso porque, para a sua escrita, o poeta encontra subsídio na famosa frase "Na natureza nada se cria, nada se perde, tudo se transforma", proferida por Lavoisier no século XVIII. Para o texto, no entanto, a constatação, voltada para o universo da química, transforma-se: nenhuma palavra que a compõe se perde e agora se torna poesia pelas mãos de Carlos de Oliveira. Esta é a primeira transformação que pode ser verificada no cenário proposto pelo poema, publicado em Sobre o Lado Esquerdo e considerado por Rui Mateus (2017b: 107) um dos livros em que se tem a "convocação de outras vozes da literatura". No caso em questão, o poeta recorre a uma frase científica, o que indica uma relação intertextual que vai além do literário.

Sobre isso, não se pode esquecer também de uma das características da relação entre o fazer poético e a própria língua. Para a estudiosa Rosa Maria Martelo (2010), a preocupação com a linguagem poética reside no fato de usar, como matéria-prima criativa, a mesma linguagem empregada em nosso cotidiano. Com isso, Gusmão (2010: 139, itálico do autor), ao corroborar o argumento de Martelo (2010), assinala que "não há uma língua poética, no sentido de uma língua (ou um idioma, de que possamos especificar um léxico e uma gramática) que sejam próprios da poesia". Em notas reunidas sob o curioso título "Da condição paradoxal da poesia", o crítico assevera que, nas conversas do dia a dia, é o contexto situacional o responsável por fornecer os indícios necessários para suprir os possíveis desentendimentos ocasionados por omissões, lapsos ou ambiguidades. Por isso, é o mesmo contexto que proporciona, quando se pensa em poesia, a sua compreensão: "Neste caso, o contexto do poema pode atrair outros poemas, do mesmo ou de outros poetas. Uma das consequências disto é que qualquer palavra, qualquer registo verbal ou gênero do discurso pode ser transformado em poema" (Gusmão 2010: 139).

A tese de Gusmão (2010) é comprovada ainda pelos primeiros versos de "Lavoisier". Estruturado em formato de coluna, assim como acontece com boa parte dos textos de Sobre o Lado Esquerdo, é-se informado de que a poesia é a "natureza variável / das palavras". Dessa maneira, o poema já indica tratar de um universo amplo, repleto de variedade, pois a 
própria natureza das palavras é marcada pela mutação - pensamento ilustrado pela transformação de uma lei científica em poema. Assim sendo, o propósito deste estudo é investigar a maneira com a qual se dá tal transformação, tendo como ponto de partida dois poemas de Carlos de Oliveira: "Retrato do autor por Camilo Pessanha (colagem)", publicado em Terra de Harmonia (1950), e "Colagem com versos de Desnos, Maiakovski e Rilke", de Sobre o Lado Esquerdo (1968). A escolha se deve em razão do fato de que ambos constituem, declaradamente, uma colagem, produzida a partir dos versos de outros poetas, de modo que é-se incitado a pensar a forma pela qual os versos adquirem sentido no novo contexto no qual estão inseridos.

\title{
Pensar a "palavra dos outros" nas duas colagens propostas por Carlos de Oliveira
}

Ou então escutemos como um verso vindo de longe costura os tempos, se escreve na areia das margens da história e assim repetidamente constela e singulariza as vozes de quem o cita $e$ ao citá-lo o transforma.

(Manuel Gusmão)

No poema "Palavras", publicado em A Noite Imóvel, Luís Quintais propõe uma reflexão acerca do discurso poético:

\author{
Palavras \\ De onde vêm, \\ ainda? \\ Eco por gente morta, \\ a dor é o limite \\ do que escuto. \\ Palavras são
}


fantasmas

na inaparente

densa

realidade. (Quintais 2017: 52 )

Assim, Quintais questiona a origem das palavras, como se pode notar nos dois primeiros versos, que aproveitam a disposição do título do poema na página. Os versos ajudam a pensar sobre o que é concluído por Manuel Gusmão (2010), em seu ensaio "Incerta chama", nas páginas iniciais de Tatuagem \& Palimpsesto. Da poesia em alguns poetas e poemas: "O poeta não tem para a poesia mais do que as palavras dos outros ou as palavras de outrem. Até porque não há outras. Há quem viva mal com isso, mas de facto nenhum de nós inventa a língua em que se fala/escreve" (Gusmão 2010: 13, destaque do autor). É por isso que, refletindo sobre o que expõe Quintais, as palavras não são mais do que fantasmas que integram a nossa realidade. São ecos produzidos por gente morta palavras que continuam a se propagar em nosso tempo, não importa quando foram ditas -, pois, advoga o linguista russo Mikhail Bakhtin (2003), “o falante não é um Adão bíblico, só relacionado com objetos virgens ainda não nomeados, aos quais dá nome pela primeira vez" (Bakhtin 2003: 300).

É em razão da impossibilidade de ser um Adão bíblico que o poeta deve lidar com o fato de que "aquele que escreve na sua instância de presente está mergulhado na história, inscreve-se na história, mesmo que apenas nas suas margens" (Gusmão 2001: 202). A passagem trata da impossibilidade de escrever sem se inserir no mesmo cenário onde estão as palavras proferidas por aqueles que nos antecederam - "eco por gente morta", já dizia o poema de Quintais. As considerações de Gusmão (2001; 2010), assim como a reflexão acerca do discurso adâmico produzida por Bakhtin (2003), são corroboradas pelos versos do brasileiro Paulo Henriques Britto (2007). Ao concluir, no texto "Crepuscular", de Tarde, que "chegamos muito tarde, e não provamos / o doce absinto e ópio dos começos" (Britto 2007: 87), o autor escreve que "todas as sílabas inimagináveis / soaram" e "nada ficou por cantar, nem mesmo o não-ter-mais-o-que-cantar [...]" (Britto 2007: 84).

Os versos pouco otimistas de Britto ganham uma nova configuração quando se relacionam com o argumento de Gusmão (2010), feito com base no pensamento de Francis 
Ponge. Nesse caso, o ensaísta pensa o poeta como um pintor que não encontra outra paleta de tinta ou pincel senão os usados por seus antecessores. Todavia, a proposição de Ponge ensina que "não se trata de limpar as cavalariças de Augias, mas de as pintar a fresco com o seu próprio esterco" (Gusmão 2010: 14). Para comentar acerca das palavras dos outros na poesia, vê-se que Ponge, resgatado por Gusmão (2010), recorre a um episódio dos doze trabalhos de Hércules, quando o herói grego recebe a ingrata tarefa de lavar o estábulo do Rei Augias, presenteado por seu pai, o deus Hélio, com um imenso rebanho de gado. Nesse processo, há um novo diálogo com o mito ao propor que, no lugar de alterar os afluentes dos rios Alfeu e Peneu, tal qual o herói grego havia feito, para que a água lave a sujeira das cocheiras, o poeta cria sua obra a partir do que se quer limpar, o esterco do estábulo.

Assim sendo, diante do explicitado até então acerca do emprego das "palavras dos outros" na poesia, não se pode deixar de mencionar a construção de "Retrato do autor por Camilo Pessanha (colagem)", no qual Carlos de Oliveira, como o próprio título indica, constrói o seu poema a partir da colagem de versos ${ }^{2}$ publicados em Clepsydra, de 1920, de Camilo Pessanha. Integrante de Terra de Harmonia, conhecido por sua intertextualidade, o poema é resultado da costura cuidadosa de "Ó meu coração, torna para trás", "Desce enfim sobre o meu coração" e "Quando voltei encontrei meus passos"5"; "Inscrição", a epígrafe7 da obra onde se leem os sonetos mencionados, é a empregada pelo poeta da Gândara para encerrar a colagem. Veja-se o poema:

\footnotetext{
A cinza arrefeceu sobre o brasido

das coisas não logradas ou perdidas:

olhos turvos de lágrimas contidas,

eu vi a luz em um país perdido. (Oliveira 2003: 139)
}

Quando se pensa o texto, é perceptível o sentimento de perda, indicado pela união dos versos "A cinza arrefeceu sobre o brasido / das coisas não logradas ou perdidas:". Vê-se que o segundo verso se torna complemento para o primeiro, além de anunciar o terceiro, porquanto o poeta da Gândara substitui o ponto final do original por dois pontos, o que transmite a ideia de um raciocínio desencadeado diante dos olhos do leitor. No cenário proposto, tem-se o indício de uma irrealização, uma vez que a cinza esfria sobre as brasas, 
onde antes havia chama e fogo, supondo uma perda. É forte a ideia de desilusão no poema, especialmente quando se tem a imagem de coisas perdidas. Ressalta-se que os dois pontos do segundo verso anunciam o lugar do sujeito, que apresenta um rosto: enquanto tenta conter as lágrimas, pode-se ver a luz em um país perdido. É o indício de que há, no fim, uma esperança para o ambiente de perda e de desilusão, diante da possibilidade para sonhar com um país que, embora perdido, talvez encontre o seu norte em um futuro indeterminado.

Claro está, quando menciona os versos de Camilo Pessanha, que Carlos de Oliveira provoca um deslocamento através dos tempos, permitindo que se pense no novo contexto proposto. Nesse ponto, é preciso recorrer ao que reflete Gusmão (2010), no ensaio “Desde que somos um diálogo", a respeito de poemas inseridos na escrita de outro autor, em um determinado período histórico. Segundo o ensaísta, é-se convidado a escutar "como o verso vindo de longe costura os tempos, se escreve na areia das margens da história e assim repetidamente constela e singulariza as vozes de quem o cita e ao citá-lo o transforma" (Gusmão 2010: 131). De maneira curiosa, o próprio significado do termo clepsidra, emprestado para o título do livro de Pessanha, também evoca o tempo, pois se refere ao relógio responsável por marcar o passar das horas da fala do orador, na Grécia Antiga. Esse tempo, tão meticulosamente calculado por um marcador, em nada reprime uma poesia portadora da capacidade de atravessar um sem número de contextos, de maneira que "parasita os códigos com que não se consegue decifrá-lo, perfura alvos sucessivos em direcção a um alvo que ainda falta imaginar. Sempre se deixa ler, nunca pela última vez" (Rubim 2003: 171).

Nota-se a maneira como "Inscrição" ganha nova significação quando inserido no rearranjo proposto por Carlos de Oliveira. Composto por quatro versos, há no poema um movimento contrário ao que se tem em "Retrato do autor por Camilo Pessanha (colagem)". Enquanto no texto de Terra de Harmonia, uma pequena luz de esperança é vista ao final, na epígrafe de Clepsydra, em seu último verso, o sujeito, abatido e desolado, espera "no chão sumir-se, como faz um verme..." (Pessanha 2000: 19). Compreende Edgard Pereira dos Reis (2014, p. 42), em sua investigação sobre o conflito existencial em Clepsydra, que é nesses versos nos quais o "sujeito lírico expressa o desejo de dissolver-se no seio do nada". Por isso, 
o poema é pautado por um pessimismo capaz de transmitir o sentimento de desolação vivido por Pessanha em seu fim de século. Desse modo, compreende António Quadros (1988: 24), é precisamente "Inscrição" aquele que, no conjunto da obra, é dotado da capacidade de passar para o leitor "sem sombra de eloquência oratória e em poucas palavras, a terrível realidade dos sentimentos de decadência e de angústia por ele vividos com desgarradora autenticidade ${ }^{8 \prime}$.

Em "Retrato do autor por Camilo Pessanha (colagem)", percebe-se que o pano de fundo para a poesia de Pessanha ganha novo sentido, de forma que o pessimismo do pósultimatum inglês se desloca para um novo cenário. Assim sendo, segundo Leonardo Gandolfi (2008: 03), apenas no poema de “Carlos de Oliveira, 'a luz' resistente de Camilo Pessanha [...] pode ser vista também na paisagem do Portugal salazarista e do pós-guerra". Para tanto, importa mencionar que Carlos de Oliveira recorre às artes plásticas ao ter na colagem o ponto de partida para a construção poética, processo informado no título do texto. Embora mencione a técnica, tem-se conhecimento de que, se considerarmos as vanguardas das pinturas, o que o poeta faz não é exatamente uma colagem. Conforme advoga Teresa Jorge Ferreira (2016), no poema em questão, "não há elementos visuais de colagem. O autor faz referência a uma técnica vanguardista, usada como analogia na poesia, mas o que há de facto é uma composição de citações textuais, de versos 'copiados'” (Ferreira 2016: 261). 0 processo, contudo, não é simples, como dá a ver Marjorie Perloff (1998). A estudiosa, baseando-se nos argumentos de David Antin, assegura que a colagem, como justaposição, coloca fim aos princípios relacionados ao que nomeia de "stronger logical relations" (Antin apud Perloff 1998: s/p), compreendido como as relações de implicação, vinculação, negação, subordinação, entre tantas outras que articulam a escrita do verso. Essas relações lógicas, antes ligadas ao poema de origem, são, de certa forma, invalidadas quando inseridas no novo texto, o que torna possível que se tenha como resultado final "um corpo central de poemas unidos pelo diálogo com a poesia de vários tempos e de várias vozes" (Martelo 1998: 348).

As várias vozes são, inclusive, uma das primeiras características a compor o processo de colagem poética, discutido pelo poeta Manuel de Freitas (2016). Dessa maneira, Freitas (2016) chama a atenção para o aspecto comunitário de que é feita a colagem, uma vez que 
remonta ao período em que não havia uma noção exata do que seria a autoria: "Cabia a uma entidade colectiva, e não a um indivíduo - invenção romântica por excelência -, transmitir e acrescentar os textos que serviam de fundamento religioso, mágico ou poético a determinadas comunidades" (Freitas 2016: 333). O texto a ser passado adiante era objeto de várias alterações, acréscimos e cortes produzidos por seus "co-autores" ao longo dos anos. Deve-se chamar a atenção, nesse contexto, para o princípio destacado por Antoine Compagnon (2007) ao discutir o trabalho da citação. Na visão do estudioso, o processo de citar remete, em um primeiro momento, ao ato infantil de cortar páginas de jornal e posteriormente reorganizá-las em uma estrutura específica. São fragmentos rearranjados, da mesma maneira como faz Carlos de Oliveira em "Retrato do autor por Camilo Pessanha (colagem)" agora com os versos de Pessanha.

Compagnon (2007) considera as citações a partir da colcha de ideias a serem produzidas por meio de combinações possíveis. No entendimento do estudioso, ao conferir nova significação ao original, aquele que escreve um texto está intimamente preso à metáfora:

Da mesma forma, toda citação é ainda - em si mesma ou por acréscimo? - uma metáfora. Toda definição da metáfora conviria também à citação; a de Fontanier, por exemplo: 'Apresentar uma ideia sob o signo de uma outra ideia mais surpreendente ou mais conhecida, que, aliás, não se liga à primeira por nenhum outro laço a não ser o de uma certa conformidade ou analogia' (Compagnon 2007: 15-16)

Pode-se pensar que é esse o princípio trabalhado por Carlos de Oliveira no poema produzido a partir do rearranjo de versos de Camilo Pessanha. A citação de cada fragmento recortado, colado agora pelo poeta da Gândara da mesma maneira como se faz uma montagem com excertos de jornais impressos, ganha nova significação. Essa possibilidade evidencia-se em outra colagem poética proposta por Carlos de Oliveira: "Colagem com versos de Desnos, Maiakovski e Rilke", publicada em Sobre o Lado Esquerdo. Chama a atenção, em um primeiro momento, que o trio selecionado revela uma imensa variação de linhagem, tendo em vista que se tem, na ordem de menção no título, versos de Desnos, francês surrealista; o russo Maiakovski, futurista, e, por fim, Rilke, pós-simbolista alemão. Ao unir os três poetas, de origens e linhagens distintas, o autor de Finisterra. Paisagem $e$ 
povoamento se mostra consciente das divergências poéticas entre cada um deles, "mas o fascínio por eles é uma das componentes na construção do poema, da poesia e da poética de Carlos de Oliveira” (Gusmão 2010: 319). É por meio da “aplicação escrita da visão bipolar à linhagem dos visionários" (Gusmão 2010: 319) que o poeta reflete sobre as palavras, tendo, como resultado final, "composições elaboradas a partir da seleção de versos dos autores identificados no título e do seu arranjo sintático e discursivo numa nova ordem de sentido, acrobaticamente obtido a partir da destreza oficinal do poeta na sua manipulação" (Mateus 2017b: 35). Leia-se o texto:

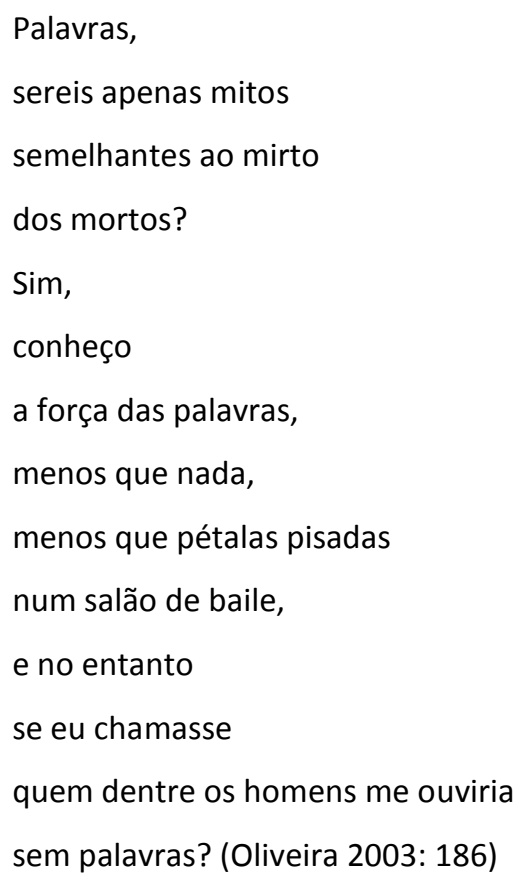

Na nova combinação proposta é possível notar o encontro de vozes mencionado por Freitas (2016) e também por Martelo (1998), pois é com versos de poetas de linhagens tão distintas que Carlos de Oliveira tece a sua reflexão acerca da força das palavras. Começa-se esta análise pela tradução, embora, assevera Gusmão (2010), com poucas alterações, feita pelo autor dos versos de Mãe Pobre (1945) do fragmento 1070 de "Rrose Selavy", publicado por Desnos em Corps et Biens, em que se lê "Mots, êtes-vous des mythes et pareils aux myrtes des morts" (DESNOS apud Gusmão 2010: 320). Existe, na inserção do fragmento no poema, um jogo de linguagem proposto pelo emprego da aliteração contida na sequência: mito, mirto e mortos. Os três termos encontram-se relacionados ao tempo e à tradição, 
como se vê: mito pressupõe a oralidade de uma narrativa transmitida aos povos, através dos anos; enquanto mirto refere-se à planta murta-comum, presente na mitologia grega e também na tradição judaica. Na mitologia, a planta é consagrada a Afrodite, a deusa da beleza, que aqui faz referência aos primeiros escritos gregos, portanto, à tradição. Já na liturgia judaica, as folhas de mirto ${ }^{10}$ são usadas no ritual para a lavagem dos mortos.

Nos versos seguintes "colados" de Maiakovski, percebe-se uma contradição proposital, na qual se confirma quase como em uma conversa: "Sim, / conheço / a força das palavras" (Oliveira 2003: 186); para, logo depois, deparar-se com um cenário que "acentua o quase nada das palavras numa sugestão, acrescentada, de fim de festa" (Gusmão 2010: 320), indicada pelos versos "menos que pétalas pisadas / num salão de baile". É o contraponto necessário para Carlos de Oliveira refletir, em seus versos finais, originários de um fragmento da Primeira Elegia de Duíno, de Rilke, sobre o reconhecimento da função das palavras a partir do questionamento: "quem dentre os homens me ouviria / sem as palavras?" (Oliveira 2003: 186). Trata-se, para lançar mão mais uma vez dos dizeres de Manuel Gusmão (2010), da tradução e adaptação dos versos "«Quem se eu gritasse me ouviria dentro [sic] as ordens dos anjos?»" (RILKE apud Gusmão 2010: 25).

A construção poética proposta pelo autor - a constatação de uma certeza, seguida posteriormente pela contradição e, enfim, concluída por um questionamento - remete às considerações de Eiras (2002), no ensaio em que discute o aspecto dialógico da obra do autor de Finisterra. Paisagem e povoamento. Enfatiza-se que o estudioso compreende como dialogismo "não apenas o confronto de teses, versões, linguagens diferentes, mas também uma íntima dúvida ou contradição de cada vez que o texto parece propor uma certeza, talvez nenhum verso permanecesse de fora" (Eiras 2002: 100). É por isso que "a interrogação inicial é a última parte a ser escrita" (Eiras 2002: 99). Aqui a pergunta final é lançada como confirmação de uma crença, a de que as palavras possibilitam que o poeta seja ouvido, pois, claro está, assegura Sophia de Mello Breyner Andresen (2015), ao evocar o pensamento de Heráclito de Éfeso em "A palavra", "«O pior de todos os males seria / A morte da palavra»" (Andresen 2015: 682).

Além disso, "Colagem com versos de Desnos, Maiakovski e Rilke" leva a pensar no que é definido por Gusmão (2010) como um chamado, “a invocação e convocação dos 
humanos à sua condição de humanos. O canto do poema é então originariamente o canto da possibilidade de êxito dessa [sic] chamamento, mesmo com o mais frágil, o mais lábil dos meios; mesmo na maior solidão" (Gusmão 2010: 321). Mais uma vez se convoca Breyner Andresen (2015), nos versos que citam o provérbio de Malinké: “"Um homem pode enganar-se em sua parte de alimento / Mas não pode / Enganar-se na sua parte de palavra»" (Andresen 2015: 682). Este chamado de que trata a poesia é apresentado no texto de Sobre o Lado Esquerdo a partir das "palavras dos outros", poetas de linhagens díspares, mas convergentes na poética de Carlos de Oliveira. A hipótese é corroborada pelos dizeres de Manuel Gusmão, quando afirma que no poema em pauta Carlos de Oliveira compõe "seu auto-retrato, feito por colagem, citação, tradução e outras transformações a partir de outros" (Gusmão 2010: 25).

Da mesma maneira, também em "Retrato do autor por Camilo Pessanha (colagem)", há a promessa de um retrato ${ }^{11}$ do autor, mas este é feito pelo rearranjo de versos de um segundo poeta, integrante do cânone português. No título do texto, Carlos de Oliveira "refere a ele próprio enquanto autor na terceira pessoa" (Ferreira 2016: 260) e dessa maneira, ao término de tudo, a única parte de sua autoria inequívoca "é escrita como se não fosse escrita por ele" (Ferreira 2016: 260). Nessa perspectiva, nota-se que, ao propor a composição de um retrato, o texto oferece a ideia de que, como acontece nas artes visuais, o autor posa diante do pintor à espera das pinceladas para criar a sua pintura. Contudo, para nossa surpresa, é Carlos de Oliveira quem conduz todos os movimentos da mão que segura o imaginário pincel. O resultado final não pode ser ignorado, como bem alerta Baudelaire (2006), no excerto que se segue o qual se refere às artes visuais que em muito se relacionam ao que se tem no poema de Terra de harmonia: "Quando vejo um bom retrato, adivinho todos os esforços do artista que inicialmente deve ter visto que se dava a ver, mas também intuído o que se ocultava" (Baudelaire 2006: 128).

Embora em "Colagem com versos de Desnos, Maiakovski e Rilke" não se perceba a mesma proposta de um retrato, realça-se que a sua constituição não é menos reveladora. Isso porque, da mesma forma como, para recorrer aos dizeres de Baudelaire, um retrato é capaz de apresentar os esforços de um artista - e a sua escolha do que se deixa de dar a ver diz tanto quanto o que é apresentado -, o texto publicado em Sobre o lado esquerdo indica 
um rearranjo de versos de poetas de tradições distintas, unidos para apresentar um monumento à palavra poética. Afinal, quem entre homens me ouviria sem as palavras?

\section{Considerações finais}

Diante da discussão empregada neste artigo, pode-se pensar a colagem poética proposta por Carlos de Oliveira como um rearranjo de versos, citações produzidas por outros poetas, estes integrantes de uma variedade de correntes literárias. Deve-se ter em mente, sob essa perspectiva, que, ao se pensar na proposta dos dois textos selecionados para este trabalho, é evidente o emprego das "palavras dos outros". No entanto, é dado a ver um deslocamento. Se, na concepção de Manuel Gusmão (2001; 2010) e também de Mikhail Bakhtin (2003), as "palavras dos outros" são o ponto de partida para o discurso literário, de modo a ser impossível precisar o seu centro, pois a obra termina por ser uma reunião de discursos, nas duas colagens propostas por Carlos de Oliveira pode-se notar que a ideia do emprego de versos de outros poetas é levada às últimas consequências. Isso porque os versos são inseridos na íntegra, sem, nesse processo, sofrer alteração em sua estrutura léxica, apenas as mudanças proporcionadas pelo novo contexto no qual está inserido - o que, por si só, provocada transformações consideráveis.

Assim sendo, pode-se ver que, em "Retrato do autor por Camilo Pessanha (colagem)" e "Colagem com versos de Desnos, Maiakovski e Rilke", textos apresentados como construções poéticas que priorizam uma montagem e uma seleção de versos de outros poetas, é colocada em prática os princípios apresentados por Carlos de Oliveira em "Lavoisier". De fato, ali, cada poema pode, finalmente, sonhar outra forma. 


\section{NOTAS}

${ }^{1}$ Há, evidentemente, outras vozes envolvidas em Sobre o Lado Esquerdo, como aponta Mateus (2017c). Os exemplos podem ser citados apenas pelos títulos dos poemas: “Colagem com versos de Desnos, Maiakovski e Rilke", "Edgar Allan Poe" e "Carlos Drummond de Andrade". É do poeta brasileiro, inclusive, um verso que em muito remete ao título do livro, Sobre o Lado Esquerdo. Em "[Cemitérios] de bolso", IV poema da seção "Cemitérios", de Fazendeiro do Ar, lê-se: "Do lado esquerdo carrego meus mortos. / Por isso caminho um pouco de banda" (Andrade 2012: 36). Ressalta-se, também, que no poema "Carlos Drummond de Andrade", tem-se os versos que remetem à Fazendeiro do ar, estabelecendo, mais uma vez, relação entre a poética dos dois autores: "Sabe lavrar / o vento / onde prosperam / o seu milho, o seu gado, / fazendeiro do ar habituado / ao arquétipo escrito" (Oliveira 2003: 188).

2 É preciso destacar que os poemas de Pessanha mencionados neste artigo foram retirados da edição publicada pela Fundação Calouste Gulbenkian, com introdução e organização de Gustavo Rubim, em 2000. O volume é um suplemento da Revista Colóquio/Letras, n. 155/156, Jan. 2000. Este esclarecimento é importante uma vez que, como é argumentado por Tereza Jorge Ferreira (2016: 262), “os títulos dos poemas de Pessanha mencionados têm sofrido algumas variações editoriais, não havendo a certeza, em muitos casos, de que tenham sido atribuídos pelo autor [...]". Por isso, ciente de que é possível que, em outras edições, os poemas mencionados apresentem outro título, se faz necessário este esclarecimento.

3 Ó meu coração, torna para trás.

Onde vais a correr, desatinado?

Meus olhos incendidos que o pecado

Queimou! Volvei, longas noites de paz.

Vergam da neve os olmos dos caminhos.

A cinza arrefeceu sobre o brasido.

Noites da serra, o casebre transido...

Cismai, meus olhos, como uns velhinhos.

Extintas primaveras, evocai-as.

- Já vai florir o pomar das macieiras.

Hemos de enfeitar os chapéus de maias. -

Sossegai, esfriai, olhos febris...

Hemos de ir a cantar nas derradeiras

Ladainhas. Doces vozes senis... (Pessanha 2000: 48)

${ }^{4}$ Desce por fim sobre o meu coração

O olvido. Irrevocável. Absoluto.

Envolve-o grave como véu de luto. 
Podes, corpo, ir dormir no teu caixão.

A fronte já sem rugas, distendidas

As feições, na imortal serenidade,

Dorme enfim sem desejo e sem saudade

Das coisas não logradas ou perdidas.

O barro que em quimera modelaste

Quebrou-se-te nas mãos. Viça uma flor,

Pões-lhe o dedo, ei-la murcha sobre a haste...

las andar, sempre fugia o chão,

Até que desvairavas, do terror.

Corria-te um suor, de inquietação... (Pessanha 2000: 23)

${ }^{5}$ Quando voltei encontrei os meus passos

Ainda frescos sobre a húmida areia.

A fugitiva hora, reevoquei-a,

- Tão rediviva!, nos meus olhos baços...

Olhos turvos de lágrimas contidas.

Mesquinhos passos, porque doidejastes

Assim transviados, e depois tornastes

Ao ponto das primeiras despedidas?

Onde fostes sem tino, ao vento vário,

Em redor, como as aves num aviário,

Até que a asita fofa Ihes faleça...

Toda esta extensa pista - para quê?

Se há-de vir apagar-vos a maré,

Com os do novo rasto que começa... (Pessanha 2000: 41)

${ }^{6}$ Eu vi a luz em um país perdido.

A minha alma é lânguida e inerme.

Oh! Quem pudesse deslizar sem ruído!

No chão sumir-se, como faz um verme... (Pessanha 2000: 19)

7 Opta-se por chamar "Inscrição" de epígrafe com base no que é afirmado por António Quadros (1988: 23), em seu texto de apresentação do volume Clepsidra: "abrindo Clepsidra, o único livro publicado por Camilo Pessanha (1920), o leitor é recebido pelos quatro versos sinópticos, dir-se-ia programáticos da epígrafe a que o autor deu o título de Inscrição". 
${ }^{8}$ Sabe-se, apenas para oferecer uma breve visão da obra de Pessanha, que o fim do século XIX, em Portugal, é marcado por duas questões essenciais. A primeira delas, segundo António Quadros (1988), é a crítica social realizada pela chamada Geração de 70, grupo encabeçado pelos escritores de Coimbra, especialmente Eça de Queirós e Antero de Quental. A segunda questão, talvez a mais grave por provocar "sobretudo, nas classes cultas, uma consciência terrivelmente infeliz" (Quadros 1988: 24), trata-se do Ultimatum inglês de 1890, quando, em uma disputa territorial na África com o Reino Unido, Portugal retirou-se das regiões localizadas entre Moçambique e Angola. Segundo W. G. Clarence-Smith (1985), o fato de o governo português aceitar o ultimato de um estrangeiro, especialmente quando se trata de um antigo aliado, proporcionou uma "intense humiliation felt by all classes in Portugal" (Clarence-Smith 1985: 83). Tendo em vista os dois fatores aqui brevemente colocados, "o país consciente, via reduzida, empequenecida, a imagem que tinha de si próprio, o que não era sem reflexos nas consciências individuais" (Quadros 1988: 24).

${ }^{9}$ A citação de Manuel de Freitas provoca a pensar no conhecido texto "A morte do autor", de Roland Barthes, e na conferência "O que é um autor?", de Michel Foucault. Em razão disso, o autor de $A$ ordem do Discurso é mencionado por Freitas (2016), como comprova a seguinte passagem: "Muito antes de Foucault, a morte do autor era serenamente admitida em prol de um valor mais alto. Música, Deus, poesia - o que Ihe quisermos chamar. Na verdade, só com o advento do romantismo se veio efectivamente a impor, enquanto delito estético, a noção de plágio" (Freitas 2016: 333-334).

${ }^{10} \mathrm{Na}$ tradição judaica e cristã, mirto é o significado de Hadassa, nome original da rainha Ester. Para o poema em questão, acredita-se que no verso em que se tem a palavra "mortos" o texto refere-se ao mirto do ritual de lavagem dos mortos.

${ }^{11}$ Sobre a discussão que se suscita a partir da elaboração de um retrato por meio da colagem poética, recomenda-se a leitura do texto "Poemas como colagens, colagens como retratos: Carlos de Oliveira e Pedro Mexia", publicado por Teresa Jorge Ferreira na elyra: Revista da Rede Internacional LyraCompoetics. n. 7, Jun/2016. 


\section{Bibliografia}

Andrade, Carlos Drummond de (2012), Fazendeiro do Ar, São Paulo, Companhia das Letras.

Andresen, Sophia de Mello Breyner (2015), Obra Poética, Lisboa, Assírio \& Alvim.

Bakhtin, Mikhail (2003), Estética da Criação Verbal, tradução de Maria Emsantina Galvão G. Pereira, São Paulo, Martins Fontes.

Baudelaire, Charles (2006), "A apologia da paisagem e a crítica do retrato", in A Pintura. Textos essenciais - os gêneros pictóricos, tradução de Magnólia Costa, São Paulo, Editora 34.

Britto, Paulo Henriques (2007), Tarde, São Paulo, Companhia das Letras.

Clarence-Smith, Gervase (1985), The Third Portuguese Empire: 1825-1975 - A study in economic imperialism, Manchester, Manchester University Press.

Compagnon, Antoine (2007), O Trabalho da Citação, tradução de Cleonice P. B. Mourão, Belo Horizonte, Editora UFMG.

Eiras, Pedro (2002), "A medição das estrelas - sobre a poesia de Carlos de Oliveira", Relâmpago, n. 11, Fundação Luís Miguel Nava, 83-105.

Ferreira, Teresa Jorge (2016), “Poemas como colagens, colagens como retratos: Carlos de Oliveira e Pedro Mexia", elyra: Revista da Rede Internacional LyraCompoetics. n. 7, Jun/2016, 257-276.

Freitas, Manuel de (2016), “Para o Sergio Lima, em forma de abraço", elyra: Revista da Rede Internacional LyraCompoetics. n. 7, Jun/2016, p. 333-337.

Gandolfi, Leonardo (2008), "Tecendo escuramente as palavras", in Anais do XI Congresso internacional da Abralic: Tessituras, interações, convergências, São Paulo, 13 a 17 de julho de 2008.

Gusmão, Manuel (2010), Tatuagem \& Palimpsesto. Da poesia em alguns poetas e poemas, Lisboa, Assírio \& Alvim.

Quintais, Luís (2017), A Noite Imóvel, Lisboa, Assírio \& Alvim. 
Martelo, Rosa Maria (1998), Carlos de Oliveira e a Referência em Poesia, Porto, Campo das Letras.

-- (2010), A Forma Informe. Leituras de poesia, Lisboa, Assírio \& Alvim.

Mateus, Rui (2017a), "Reescrever o definitivo: o lugar das traduções de Camões e Shakespeare na poesia de Carlos de Oliveira", in Colóquio/Letras: Carlos de Oliveira, n. 195, Maio/Ago, Fundação Calouste Gulbenkian, 34-48.

-- (2017b), “Recreio e recriação. Dois nomes para a reescrita de Sá de Miranda e Manuel Bandeira em Carlos de Oliveira", in Revista do CESP, v.37, n.57, Faculdade de Letras da Universidade Federal de Minas Gerais, 97-113.

Oliveira, Carlos de (1995), O aprendiz de Feiticeiro, Lisboa, Livraria Sá da Costa Editora.

-- (2003), Trabalho Poético, Lisboa: Assírio \& Alvim.

Perloff, Marjorie (1998), "Collage and poetry", in Marjorie Perloff: Modern and Postmodern Poetry and Poetics, <http://marjorieperloff.com/essays/collage-poetry/> (último acesso em: 26/01/2017).

Pessanha, Camilo (2000), "Clepsydra", in Suplemento especial da Revista Colóquio/Letras, Documentos, n. 155/156, edição organizada por Gustavo Rubim e ilustrada por Cruzeiro Seixas, Lisboa, Fundação Calouste Gulbenkian.

Quadros, António (1988), "Introdução à vida e obra de Camilo Pessanha", in Clepsidra, Sintra, Publicações Europa-América, 11-30.

Rubim, Gustavo (2003), Arte de Sublinhar, Coimbra, Angelus Novus. 
Patrícia Resende Pereira tem doutorado em Estudos Literários pela Universidade Federal de Minas Gerais (UFMG), na área de pesquisa Literaturas Modernas e Contemporâneas, tendo defendido a tese em agosto de 2018. Fez o doutorado-sanduíche na Universidade do Porto, em 2017, com financiamento da Bolsa de Investigação em Cultura Portuguesa para Estrangeiros da Fundação Calouste Gulbenkian. Tem mestrado em Estudos de Linguagens pelo Centro Federal de Educação Tecnológica de Minas Gerais (Cefet-MG), em 2012. Faz parte, desde 2011, do Pólo de Estudos em Poesia Portuguesa Moderna e Contemporânea, da UFMG. 